\title{
ALTERAÇÕES DO PROTEINOGRAMA DO LIQÜIDO CEFALORRAQUIDIANO NA POLIRRADICULONEURITE
}

\author{
A. Spina-França * \\ Sylvio SaRaiva *
}

Delank e Machetanz ${ }^{4}$, analisando por eletroforese as frações protêicas de amostras de líqüido cefalorraquidiano (LCR) com dissociação proteínocitológica, verificaram alterações que nem sempre são do mesmo tipo e que, em geral, estão relacionadas ao processo mórbido em curso. A dissociação proteíno-citológica do LCR na polïrradiculoneurite se caracteriza por certas peculiaridades do perfil eletroforético que, segundo os achados de Steger ${ }^{14}$ em dois casos, aproximam o proteinograma do LCR do tipo encontrado habitualmente para o sôro sangüíneo (sôro); nos dois casos, observou êste autor um aumento do teor de $\gamma$-globulina e, em um, aumento da $\alpha_{1}$-globulina, com inversão da relação entre as $\alpha$-globulinas. Alterações semelhantes do proteinograma do LCR na polirradiculoneurite são referidas por Vymazal e Hanzal ${ }^{17}$. Lemmen e col. ${ }^{8}$, estudando dois casos, chamam também a atenção para a semelhança do perfil protêico do LCR e do sôro na polirradiculoneurite. Tendo em vista as modificações do proteinograma do LCR, Scarzella ${ }^{10}$ considera que a dissociação proteíno-citológica observada na polirradiculoneurite pode ser atribuida a um mecanismo de transudação de proteínas do sangue para o LCR.

No presente estudo, os achados referentes ao proteinograma do LCR na polirradiculoneurite são analisados e suas relações com o proteinograma do sôro são discutidas e caracterizadas.

\section{MATERIAL E MÉTODO}

O proteinograma do LCR foi estudado em 7 pacientes com polirradiculoneurite. O critério de seleção dos casos obedeceu aos principios estabelecidos por Guillain ${ }^{8}$ para caracterizar a sindrome. Assim, em todos, havia acometimento sensitivo-motor de tipo periférico, múltiplo e simétrico, de início agudo e com evolução benigna, acompanhado de dissociação proteino-citológica no LCR lombar.

Em todos os casos foi estudado o proteinograma de uma amostra de LCR lombar e nos 5 primeiros o de uma amostra de sôro. Os exames foram feitos na mesma ocasiāo, dentro do primeiro mês de evolução da doença e antes do início da terapêtica. Nas amostras de LCR estudadas foi feito também exame citológico,

Trabalho da Clinica Neurológica do Hospital das Clinicas da Fac. de Med. da Univ. de São Paulo (Prof. A. Tolosa): *assistente extranumerário. 
determinação da taxa de proteinas totais e exame imunológico (reações de fixação do complemento para sifilis e para cisticercose).

A taxa de proteinas totais do LCR foi determinada pelo método do VDRL, sumariado em outra publicação ${ }^{13}$ e o estudo das fraçōes protēicas do LCR e do sôro foi feito por eletroforese em papel, segundo a técnica descrita anteriormente ${ }^{11}$.

Para avaliar as peculiaridades das alterações do proteinograma do LCR em relação ao do sôro foi calculada a relação entre o teor de cada fração encontrado para um e para outro material, nos casos em que as frações protêicas de ambos foram estudadas.

Para a interpretação dos resultados foram adotados como critérios de normalidade aquêles publicados anteriormente, tanto para a proteinorraquia total 13 como para o perfil eletroforético ${ }^{12}$.

\section{RESULTADOS}

Em tôdas as amostras de LCR era normal o número de leucócitos, havia aumento da taxa de proteinas totais e o exame imunológico foi negativo.

A taxa de proteinas totais e os teores relativos (\%) achados para as fraçoes protêicas das amostras de LCR são referidos no quadro 1 . Os percentuais referentes às frações protêicas das amostras de sôro são referidos no quadro 3 e, no quadro 4, os valores da relação entre o teor de cada fração protêica no LCR e no sôro. Para facilitar a interpretação dos resultados do proteinograma do LCR são referidos, no quadro 2, os valores normais para o teor das diversas frações e, no gráfico 1 , são representados em relação aos valores dêste quadro os resultados obtidos para os casos estudados.

\section{Frações protêicas}

\begin{tabular}{|c|c|c|c|c|c|c|c|}
\hline \multirow{2}{*}{ Casos } & \multirow{2}{*}{$\begin{array}{c}\text { Pré- } \\
\text { albumina }\end{array}$} & \multirow[t]{2}{*}{ Albumina } & \multicolumn{4}{|c|}{ Globulinas } & \multirow{2}{*}{$\begin{array}{c}\text { Proteina } \\
\text { totais }\end{array}$} \\
\hline & & & $\alpha_{1}$ & $\alpha_{2}$ & $\beta$ & $\gamma$ & \\
\hline $1 \ldots \ldots \ldots \ldots$ & 0,5 & 50,0 & 10,0 & 14,0 & 13,0 & 12,5 & 78 \\
\hline $2 \ldots \ldots \ldots \ldots$ & 2,0 & 51,5 & 6,5 & 13,5 & 18,0 & 8,5 & 64 \\
\hline $3 \ldots \ldots \ldots \ldots$ & 3,0 & 48,5 & 12,0 & 14,0 & 13,5 & 9,0 & 83 \\
\hline $4 \ldots \ldots \ldots \ldots$ & 1,5 & 43,5 & 12,0 & 10,0 & 15,5 & 17,5 & 148 \\
\hline $5 \ldots \ldots \ldots \ldots$ & 1,5 & 56,0 & 10,0 & 10,5 & 14,0 & 8,0 & 132 \\
\hline $6 \ldots \ldots \ldots \ldots$ & 0,5 & 46,0 & 12,0 & 14,5 & 12,0 & 15,0 & 80 \\
\hline $7 \ldots \ldots \ldots \ldots$ & 2,0 & 40,5 & 13,0 & 10,5 & 14,0 & 20,0 & 90 \\
\hline
\end{tabular}

Quadro 1 - Teores (\%) correspondentes às frações protêicas das amostras de LCR estudadas e concentração protêica total respectiva $(\mathrm{mg} / 100 \mathrm{ml})$.

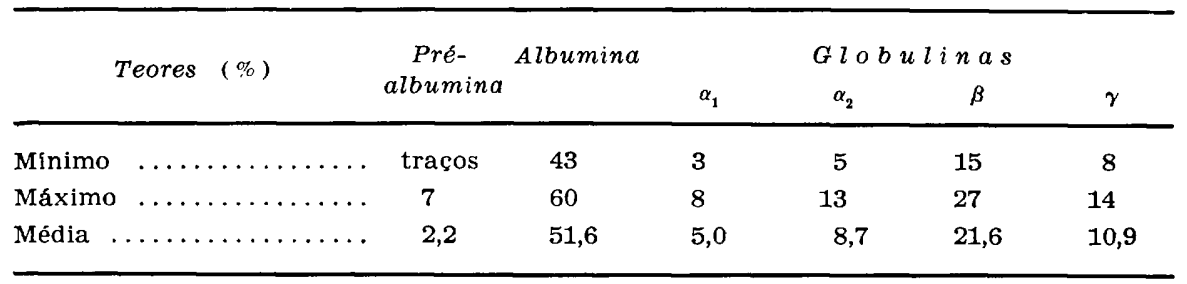

Quadro 2 - Teores relativos (\%) maximo e minimo achados para as fracóes protêicas do LCR de 30 pessoas normais e a média respectiva. 


\begin{tabular}{|c|c|c|c|c|c|}
\hline \multirow{2}{*}{ Casos } & \multirow[t]{2}{*}{ Albumina } & \multicolumn{4}{|c|}{ Globulinas } \\
\hline & & $\alpha_{1}$ & $\alpha_{2}$ & $\beta$ & $\gamma$ \\
\hline 1 & 54,5 & 4,5 & 13,5 & 13,5 & 14,0 \\
\hline $2 \ldots$ & 46,0 & 6,0 & 12,0 & 14,0 & 22,0 \\
\hline $3 \ldots \ldots \ldots \ldots \ldots$ & 52,0 & 2,5 & 12,0 & 13,0 & 20,5 \\
\hline $4 \ldots \ldots \ldots \ldots$ & 46,5 & 6,5 & 14,5 & 12,5 & 20,0 \\
\hline$\ldots \ldots$ & 59,0 & 4,5 & 8,0 & 14,0 & 14,5 \\
\hline
\end{tabular}

Quadro 3 - Teores (\%) correspondentes às fraçōes protêicas das amostras de sôro sangüineo estudadas.

\begin{tabular}{|c|c|c|c|c|c|}
\hline \multirow{2}{*}{ Casos } & \multirow{2}{*}{ Albumina } & \multicolumn{4}{|c|}{ Globulinas } \\
\hline & & $\alpha_{1}$ & $\alpha_{2}$ & $\beta$ & $\gamma$ \\
\hline $1 \ldots \ldots \ldots \ldots \ldots$ & 0,9 & 2,2 & 1,0 & 1,0 & 0,9 \\
\hline $2 \ldots \ldots \ldots \ldots \ldots$ & 1,1 & 1,1 & 1,1 & 1,3 & 0,4 \\
\hline $3 \ldots \ldots \ldots \ldots \ldots$ & 0,9 & 4,8 & 1,2 & 1,0 & 0,4 \\
\hline $4 \ldots \ldots \ldots \ldots \ldots$ & 0,9 & 1,8 & 0,7 & 1,2 & 0,9 \\
\hline $5 \ldots \ldots \ldots \ldots \ldots$ & 0,9 & 2,2 & 1,3 & 1,0 & 0,6 \\
\hline
\end{tabular}

Quadro 4 - Relação entre o percentual relativo a cada fração protêica no $L C R \boldsymbol{e}$ no sôro.

Gráfico 1 - Comportamento dos teores encontrados para as frações protêicas do LCR nos 7 casos de polirradiculoneurite em relação aos teores normais respectivos ( $\mathrm{M}$ limite superior normal; $\mathrm{m}$, limite inferior normal; $\overline{\mathrm{x}}$, média normal).

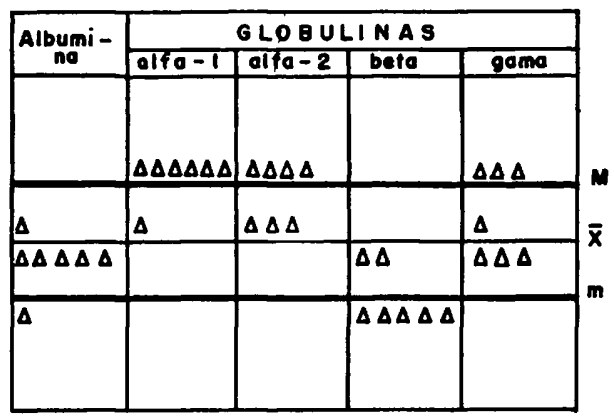

\section{COMENTARIOS}

Alterações do proteinograma do LCR na polirradiculoneurite - Em relação ao proteinograma do LCR normal não foram encontradas alterações dos teores da pré-albumina e em apenas uma amostra (caso 7) estava diminuído o teor de albumina, sendo normal nas demais. Foram verificadas alterações do teor das diversas globulinas que podem ser resumidas da se- 
guinte forma: em todos os casos os teores de $\alpha$-globulinas situavam-se acima da média normal, estando aumentado o teor da $\alpha_{1}$-globulina em 6 (casos 1 , 3, 4, 5, 6 e 7) e da $\alpha_{2}$-globulina em 4 (casos 1, 2, 3 e 6); em dois casos havia inversão da relação entre estas globulinas, predominando o teor da fração $\alpha_{1}$; os teores de $\beta$-globulina situavam-se, em todos os casos, abaixo da média normal, estando diminuídos em 5 (casos 1, 3, 5, 6 e 7); distribuiam-se os teores de $\gamma$-globulina ao redor da média normal em 4 casos; em três (casos 4, 6 e 7) o teor da $\gamma$-globulina estava aumentado, ultrapassando o teor da fração $\beta$ e invertendo a relação habitual entre essas fraçōes protêicas no LCR.

Em conjunto, pode-se dizer que o proteinograma do LCR na polirradiculoneurite se caracteriza por uma participação maior das $\alpha$-globulinas e, por vêzes, da $\gamma$-globulina, que é compensada por uma diminuição do teor relativo de $\beta$-globulina.

O comportamento particular das $\alpha$-globulinas, pôsto em evidência nesta investigação, representa um fato que merece ser salientado porque o critério de seleção adotado permitiu excluir aquêles processos periféricos de tipo agudo que não se enquadram na definição da síndrome de Guillain-Barré ${ }^{6}$. Por outro lado, só foram estudados casos que se achavam no período inicial de evolução da doença e nos quais ainda não tinha sido iniciada a terapêutica. Por não terem sido adotados êstes critérios é que talvez se expliquem os achados inconstantes em relação às $\alpha$-globulinas, registrados por outros autores, como se mostrou inicialmente. O aumento inconstante da $\gamma$-globulina nos casos apresentados pode decorrer do curto periodo de evolução dos casos, não tendo ocorrido ainda modificações de ordem metabólica geral do sistema retículo-endotelial que possam repercutir sôbre o teor dessa fração no LCR.

Alterações da relação entre o proteinograma do LCR e do sôro na polirradiculoneurite - Habitualmente encontram-se no LCR teores de albumina e de $\alpha$-globulinas semelhantes aos encontrados no sôro; o teor de $\beta$-globulina no LCR corresponde a 1,5 a duas vêzes no sôro e o de $\gamma$-globulina, à metade ${ }^{12}$. Pelo quadro 4 verifica-se que as variaçōes da relação entre o teor de cada fração no LCR e no sôro situam-se ao redor do normal para a albumina e para $\alpha_{2}$-globulina e, em três casos, para a $\gamma$-globulina. Está aumentada, em dois casos, a relação obtida para esta última e diminuida, em todos os casos, a da $\beta$-globulina. As maiores alterações foram encontradas para a relação $\mathrm{LCR} /$ sôro da $\alpha_{1}$-globulina, aumentada em todos os casos, atingindo como máximo o valor de 4,8 .

Em conjunto, pode-se verificar que tendem para a unidade os valores das relações entre o teor no LCR e no sôro das frações albumina, $\alpha_{2}$-globulina, $\beta$-globulina e, em alguns casos, da $\gamma$-globulina, confirmando a semelhança referida para o proteinograma do LCR e do sôro na polirradiculoneurite. Faz exceção apenas o comportamento especial verificado em relação à $\alpha_{1}$-globulina. 
Tipo das alterações do proteinograma do LCR na polirradiculoneurite - Em contraposição ao tipo normal do proteinograma do LCR é descrito o tipo sérico, isto é, aquêle no qual o perfil protêico do LCR é idêntico ao encontrado para o sôro. Entre êsses extremos do proteinograma do LCR situa-se o perfil de tipo misto, que lembra aquêle que se obtém quando as proteínas do LCR e do sôro são misturadas e analisadas em conjunto. Segundo Bauer ${ }^{2}$, o proteinograma do LCR dêste último tipo é semelhante ao do sôro mas guarda certas características que lhe são próprias.

Nos casos estudados, as relações guardadas entre si pelos teores das diversas frações protêicas no LCR e no sôro (quadro 4) demonstram a semelhança existente entre os perfis; as diferenças referentes ao teor de certas frações e a presença no LCR da pré-albumina são elementos suficientes para não permitir referir o proteinograma do LCR na polirradiculoneurite como de tipo sérico ${ }^{10}, 14$, mas, como de tipo misto. Em vista de ter ocorrido, associadamente, aumento do teor de $\alpha$-globulinas, poderiam os achados ser englobados no subtipo "perfil misto acompanhado de aumento de $\alpha$-globulinas", segundo a terminologia adotada por Bauer ${ }^{2}$.

Equilíbrio protêico entre LCR e sôro na polirradiculoneurite - O mecanismo de ultrafiltração que regula a passagem das proteínas plasmáticas para o LCR, em condições normais, garante um equilíbrio entre ambos, pelo qual a representação da albumina e das $\alpha$-globulinas no proteinograma de cada um dêles é a mesma, sendo de quase o dôbro a representação de $\beta$-globulina no do LCR e de cêrca da metade a da $\gamma$-globulina, como já foi referido. Do aumento da permeabilidade da barreira hêmato-liquórica decorre aumento da ultrafiltração protêica a partir do plasma, elevando-se a proteinorraquia total. Ao mesmo tempo modifica-se o equilibrio entre as frações protêicas do LCR e do sôro, do que resultam tipos patológicos de proteinograma do LCR; os perfis de tipo misto e de tipo albumínico (aumento do teor de albumina) representam as alterações mais comuns nessas condições, segundo Laciga e Zidová ${ }^{7}$.

$\mathrm{Na}$ polirradiculoneurite a modificação do equilíbrio protêico entre o LCR e o sangue acarreta para quase tôdas as frações protêicas uma participação semelhante no proteinograma de um e de outro, tendendo para a unidade a relação entre os teores respectivos, conforme foi verificado nos casos estudados. Faz exceção o comportamento evidenciado para a $\alpha_{1}$-globulina, para a qual a relação LCR/sôro se mostrou sempre acima da unidade, chegando a participação dessa globulina no proteinograma do LCR a representar quase 5 vêzes a encontrada para o do sôro (caso 3). Uma modificação específica da barreira, quanto à sua permeabilidade para esta fração poderia explicar o achado; não se pode afastar, entretanto, que esta condição particular seja devida a uma estase relativa dessa globulina no LCR por uma reabsorção menor, em semelhança ao que pode ocorrer com a albumina. No LCR de estase (bloqueio do canal raquidiano) o proteinograma costuma 
ser de tipo albumínico, isto é, apresenta aumento 'do teor desta fração, que ultrapassa os percentuais achados no proteinograma do sôro. Nessas condições já foi demonstrada a deficiência de reabsorção de albumina marcada com iôdo radioativo ${ }^{16}$. Na polirradiculoneurite êsse mecanismo não foi confirmado para a albumina, empregando o mesmo método de investigação ${ }^{1}$, com o que concordam os resultados do presente estudo por não terem sido registrados aumentos do teor desta fração e/ou aumento da relação respectiva entre sua participação no proteinograma do LCR e do sôro. Não há estudos quanto à reabsorção de globulinas marcadas na polirradiculoneurite e a hipótese aventada em relação à $\boldsymbol{\alpha}_{1}$-globulina necessita de confirmação. A estase desta globulina poderia decorrer de alterações estruturais sofridas durante sua permanência no LCR, na dependência do processo etiopatogênico. Que modificações estruturais desta fração podem ocorrer no LCR é fato conhecido ${ }^{3} \mathrm{e}$, no caso, poderiam estar ligadas a modificações de suas relações com substâncias de que é carreadora, como lipo e glicoproteínas e seromucóide que, com ela, provêm do sangue ${ }^{5,15}$. O aumento do teor de $\alpha_{2}$-globulina no LCR, encontrado em 4 casos, pode ser secundário ao aumento do teor desta fração no sôro, conforme foi verificado em três dêles, em que êste último foi estudado. Da mesma forma pode ser explicado o aumento da $\gamma$-globulina, que foi discreto nos três casos em que foi observado, não atingindo a niveis suficientemente elevados, para serem sugestivos de ser produzida pelo sistema retículo-endotelial diretamente relacionado ao espaço liquórico, de acôrdo com as investigações de Matiar e Schmidt ${ }^{9}$. A mesma interpretação foi adotada por Steger ${ }^{14}$ para explicar o aumento desta globulina observado no proteinograma do LCR dos casos de polirradiculoneurite por êle estudados.

\section{RESUMO E CONCLUSOES}

Foi estudado por eletroforese em papel o proteinograma do LCR de 7 pacientes com polirradiculoneurite; em 5 foi estudado também o proteinograma do sôro pelo mesmo método. As alteraçōes verificadas permitem caracterizar o proteinograma do LCR nesta afecção como sendo de tipo misto, acompanhado de aumento de $\alpha$-globulinas, segundo a classificação de Bauer. Foi mostrado que as modificações observadas no teor das diversas frações protêicas no LCR podem ser secundárias a alterações verificadas no sôro e que podem decorrer de distúrbios do mecanismo de ultrafiltração das proteinas do sangue para o LCR, por modificaçōes da barreira hêmato-liquórica. O comportamento particular da $\alpha_{1}$-globulina é salientado; seu teor estava aumentado no LCR em 6 casos e, em relação ao teor desta globulina no proteinograma do sôro, sua participação no do LCR chegou a ser quase 5 vêzes maior. Para explicar esta observação, além da hipótese anterior, é lembrada a de poderem ocorrer no LCR, nos casos de polirradiculoneurite, modificações estruturais desta globulina e/ou das relações entre ela e as substâncias de que é carreadora, modificando sua reabsorção no sentido de se produzir uma estase relativa. 


\section{SUMMARY AND CONCLUSIONS}

\section{Changes in the cerebrospinal fluid protein fractions in Guillain-Barré} syndrome.

The cerebrospinal fluid (CSF) protein fractions were studied in 7 cases of Guillain-Barré syndrome by paper electrophoresis; in 5 of them the serum protein fractions were studied also. The investigation in each case was carried in the first month following the onset of the disease and prior to the beginning of therapeutics. There was a protein-cytologic dissociation in the CSF in all the cases.

It is possible to classify the changes found in the CSF proteins as being similar to the "mixed type" pattern ("Mischelektrophoresediagramm", Bauer) with an associated increase in the participation of $\alpha$-globulins. It was shown that the changes in the CSF protein fractions may be secondary to those that occurred in the serum and that they are dependent on disturbances in the ultrafiltration of blood proteins to the CSF. Such disturbances are possibly caused by the changes brought about by the disease in the bloodCSF barrier.

The special behaviour of $\alpha_{1}$-globulin is shown by its relative content in the CSF. It was increased in 6 cases and its relation to the serum content was always superior to 1 (the maximum value observed was 4.8 ). The disturbances in the blood-CSF barrier are pointed out in the explanation of these findings, although the occurrence of a relative stagnation of this protein fraction in the CSF may play an important role also. Structural changes in this globulin and/or in the substances which are bound to it may modify the rate of its reabsorption, thus bringing about a relative stagnation.

\section{REFERENCIAS}

1. AUSTIN, J. H. - Recurrent polyneuropathies and their corticosteroid treatment. Brain, 81(2):157-192, 1958. 2. BAUER, H. - Über die Bedeutung der Papier Elektrophorese des Liquors für die klinische Forschung. Deutsch. Ztschr. f. Nervenh., 170:381-401 (setembro) 1953. 3. CLAUSEN, J. - Immunoelectrophoretic investigations of normal and pathologic cerebrospinal fluids. World Neurol., 1:479490 (dezembro) 1960. 4. DELANK, H. W.; MACHETANZ, E. - Das Syndrom der "proteino-cytologischen Dissoziation" im Liquor cerebrospinalis. Deutsch. Ztschr. f. Nervenh., 174:189-198 (dezembro) 1955. 5. DENCKER, S. J.; BRONNESTAM, R.; SWAHN, B. - Demonstration of large blood proteins in CSF. Neurology, 11:441444 (maio) 1961. 6. GUILLAIN, G. - Radiculoneuritis with acellular hyper-albuminosis of the cerebrospinal fluid. Arch. Neurol. a. Psychiat., 36:975-990 (novembro) 1936. 7. LACIGA, Z.; ZIDOVA, V. - The paper-electrophoresis contribution to the determination of types of cerebrospinal fluid: formulae in nerve diseases. Abstr. Communic. 1st. Congress Czechoslovak Neurologists, Jezenik.-Lazné (outubro, 8-13) 1956, págs. 18-19. 8. LEMMEN, L. J.; DREW, A. L.; GLIMM, J. C.; HIGGINS, J. E. - Study of cerebrospinal fluid with paper electrophoresis: III The Guillain-Barré syndrome (preliminary report). Univ. Mich. Med. Bull., 23:102110, 1957. 9. MATIAR, H.; SCHMIDT, C. - Der Erhöhung der Gamma-globuline 
im Liquor. Deutsch. Ztschr. f. Nervenh., 178:300-312 (outubro) 1958. 10. SCARZELLA, R. - Sulla patogenesi della sindrome di Guillain-Barré-Strohl (contributo clinico e biochimico). G. Psichiat. e Neuropatol., 85:1-53, 1957. 11. SPINA-FRANCA, A. - Eletroforese das proteinas do líquido cefalorraquidiano: III - Técnica. Arq. Neuro-Psiquiat. (São Paulo), 16:236-242 (setembro) 1958. 12. SPINA-FRANÇA, A. - Eletroforese das proteínas do liquido cefalorraquidiano: IV - Valores normais. Arq. Neuro-Psiquiat. (São Paulo), 18:19-28 (março) 1960. 13. SPINA-FRANCA, A.; AMAR, I. - Valores normais da concentração protêica do liquido cefalorraquidiano: variações ligadas ao local de colheita da amostra. Arq. Neuro-Psiquiat. (São Paulo), 19:220-225 (setembro), 1961. 14. STEGER, J. - Blut und Liquor veränderungen bei der Polyneuritis (mit vorläufigen elektrophoretischen Ergebnissen). Deutsch. Ztschr. f. Nervenh., 170:106-121 (junho) 1953. 15. SWAHN, B.; BRONNESTAM, R.; DENCKER, S. J. - On the origin of lipoproteins in the cerebrospinal fluid. Neurology, 11:437-440 (maio) 1961. 16. SWEET, W. H. - Diseases of the nervous system. Ann. Rev. Med. (Stanford), 7:441-460, 1956. 17. VYMAZAL, J.; HANZAL, F. - Changes in albumen fractions in the serum and cerebrospinal fluid in cases of neuro-infections. Abstr. Communic. 1st. Congress Czechoslovak Neurologists, Jezenik-Lazné (outubro, 8-13) 1956, págs. 19-20.

Clinica Neurológica - Hospital das Clinicas da Fac. Med. da Univ. de São Paulo - Caixa Postal 3461 - São Paulo, Brasil. 